\title{
Taguchi Orthogonal Test on Granule Properties and Porosity Distribution in Sintering Bed using High-resolution X-ray Computed Tomography
}

\author{
Jianuo XU, Hao ZHOU, ${ }^{*}$ Mingxi ZHOU, Shihao HU and Yuhang ZUO \\ State Key Laboratory of Clean Energy Utilization, Institute for Thermal Power Engineering, Zhejiang University, Hangzhou, \\ 310027 P.R. China.
}

(Received on September 3, 2019; accepted on November 21, 2019)

\begin{abstract}
Granulation and packing of iron ores are highly essential for having a strong function with packed bed porosity distribution, and further affecting the subsequent sintering process. In this study, high-resolution X-ray computed tomography technique was applied to investigate the influence of moisture, hydrated lime and concentrate levels on granule properties and porosity distribution of packed bed based on the Taguchi orthogonal array tests, and the optimum granulation factors combination was determined by the defined porosity segregation degree for improving packed bed homogeneity. Moisture was found to be the dominant factor affecting granule size with a major percent contribution of $94.42 \%$. Bulk bed porosity was significantly affected by all three selected factors of moisture, hydrated lime and concentrate levels. The percent contribution order was shown as hydrated lime $(55.10 \%)>$ moisture $(29.12 \%)>$ concentrate $(14.36 \%)$. The whole packed bed was found to exhibit significant inhomogeneity. Axial porosity increases from the bottom upwards along the packed bed height, and radial porosity appears a symmetric parabolic distribution where porosity achieves the minimum of 0.3 at bed center and increases sharply near the wall. To achieve the homogeneous packed bed of iron ore granules, the optimum granulation factors combination for decreasing axial and radial porosity segregation are determined as $6.8 \%$ moisture, $4 \%$ hydrated lime, $0 \%$ concentrate and $5.8 \%$ moisture, $4 \%$ hydrated lime, $0 \%$ concentrate, respectively. The results provide the theoretical guidance for granulation and packing in iron ore sintering to improve sintering yield and quality.
\end{abstract}

KEY WORDS: iron ore sintering; granule properties; bed porosity distribution; X-ray computed tomography; Taguchi orthogonal test.

\section{Introduction}

Iron ore sinter typically constitutes more than $70 \%$ of the blast-furnace ferrous feed, leading iron ore sintering of great importance in ironmaking plants. In the sintering process, raw materials consisting of iron ores, fluxes, coke breeze and return fines are initially proportional blended in a tumbling drum and made into granules with desirable size, size distribution and strength during the granulation process. The produced granules then are feed onto a moving sinter strand, after which the top of the bed is ignited and the flame front descends down the bed of granules under the application of suction. After complicated physicochemical phenomena during sintering, the granule feeds are converted into a porous sintered product, which is then fed to the blast furnace for ironmaking.

Granulation is a highly important stage in the overall sintering process. According to the well-known Ergun equation, ${ }^{1)}$ the gas flow velocity across the packed bed is

\footnotetext{
* Corresponding author: E-mail: zhouhao@zju.edu.cn

DOI: https://doi.org/10.2355/isijinternational.ISIJINT-2019-562
}

a function of granule packed bed characteristics, such as mean granule diameter, bed porosity and granule shape, which significantly influence the flame front speed, bed temperature profile versus time as well as heat transfer, and subsequently determines the final sintering productivity and quality of the sinter. ${ }^{2-4)}$ It is widely accepted that the principal mechanism of granulation is the layering of adhering fine granules onto the coarser nucleus granules under the action of the liquid bridge formed by water. ${ }^{5,6)}$ Reportedly, moisture available for granulation is the paramount factor to determine the granule growth mechanism and further greatly affect granulation effectiveness. ${ }^{7)}$ It is considered that the addition of water increases the granule mean size and tightens the size distribution, as well as greatly influences the packed bed porosity due to the wet granules deformation. ${ }^{2,8,9)}$

Besides, the inherent physicochemical properties of feed components such as size distribution, density, granule shape, surface characteristics as well as moisture capacity ${ }^{10-13)}$ also contribute to the granule packed bed properties. The fine materials added in the granulation feed such as concentrate and hydrated lime increase the share of ultra-fines as well as 
affect the overall granule shape and surface characteristics, hence play important roles in the granulation mechanisms. Lister and Waters ${ }^{14)}$ found that the effect of fine granules on granulation is complex, granulation effectiveness decreases with the increasing amount of fines $(-0.25 \mathrm{~mm})$ but increases as the mean size of these granules decreases. Khosa and Manuel ${ }^{15)}$ quantified the effect of granules size on granulation across a range of iron ore types by developing a simple model, it was found that for most iron ores, an increase in the number of granules close to $0.1 \mathrm{~mm}$ size range had the greatest effect of reducing permeability. Nyembwe et al. ${ }^{10,16)}$ proposed four mechanisms governing the granule growth with sinter mixtures that containing iron ore fines, concentrate and micropellets, and found that adding concentrate produced granules with smaller mean size. Besides, they investigated the effect of concentrate additions on the permeability of the sinter mixture. The results confirmed that the addition of concentrate to the sinter mix significantly affected the porosity of packed bed through changing granule size, porosity and angle of repose. ${ }^{17)}$ Zhou et al. ${ }^{18,19)}$ explored the effects of a wide range of water, concentrate and hydrated lime addition levels on the granule structure and packed bed properties, and an improved semi-empirical green bed porosity model was proposed considering the deformation of granules happened to the adhering layer.

Although the effects of moisture and feed fines on granule size and bulk bed porosity had been widely investigated, their relative importance is unclear. Besides, to the best of author's knowledge, the detailed three-dimensional structure of iron ores packed bed is rarely revealed. In recent decades, X-ray computed tomography (XCT), one of the well-established non-destructive techniques, is being increasingly attractive in packed bed structure investigation for its significant advantages of reconstructing the real threedimensional internal structure of packed bed and directly obtaining the spatial information of structure properties such as granule size, bulk porosity and porosity distribution. ${ }^{20-22)}$
However, XCT technique is seldom applied to the packed bed of iron ore granules, where understanding the threedimensional packed bed structure is of practical significance for improving iron ore sintering yield and quality.

In the present study, the XCT technique was applied to derive the three-dimensional structural information of packed bed including granule mean diameter, bulk porosity, and porosity distribution. And the axial and radial porosity segregation were defined to evaluate the homogeneity of iron ore granule packed bed. In addition, Taguchi experiment design and ANOVA analysis were conducted to analyze the relative importance of moisture, hydrated lime and concentrate levels on granule properties and porosity distribution, and determine the optimum granulation factors combination for improving packed bed homogeneity.

\section{Experimental}

\subsection{Granulation}

Raw materials used in this study are composed of iron ore fines, concentrate, coke breeze, fluxes, binder (hydrated lime) and return fines with different size $(-3.35 \mathrm{~mm}$ and $-5+3.35 \mathrm{~mm}$ ). The size distribution and physical properties of raw materials above are available in previous studies. ${ }^{18,19)}$ Hydrated lime and concentrate are classified as ultra-fines, the mean volume diameter of hydrated lime is $12.7 \mu \mathrm{m}$, the apparent density $1760 \mathrm{~kg} / \mathrm{m}^{3}$, the porosity $70.1 \%$; and $92.3 \mu \mathrm{m}, 4680 \mathrm{~kg} / \mathrm{m}^{3}, 46.2 \%$ respectively for concentrate. A typical ore blend of five iron ore fines used in Asia-Pacific region, namely 16.7 mass\% AUS1 fines, 33.3 mass\% AUS2 fines, 16.7 mass $\%$ AUS3 fines, 16.7 mass\% BRA1 fines, 16.7 mass \% BRA2 fines, was used as a base blend in this study. ${ }^{18,19)}$ Table 1 shows the raw materials composition details referred to the literature. ${ }^{19)}$

Granulation process was performed in a stainless steel cylindrical drum with the diameter of $500 \mathrm{~mm}$ and length of $300 \mathrm{~mm}$. Approximately $13.6 \mathrm{~kg}$ blended raw materials were introduced into the rotary drum and dry mixed for 2

Table 1. Raw materials compositions of the granule mix (mass $\%$ ).

\begin{tabular}{|c|c|c|c|c|c|c|}
\hline \multirow{2}{*}{$\begin{array}{l}\text { Blend } \\
\text { Basis }\end{array}$} & \multicolumn{2}{|c|}{$0 \% \mathrm{M}$} & \multicolumn{2}{|c|}{$10 \% \mathrm{M}$} & \multicolumn{2}{|c|}{$30 \% \mathrm{M}$} \\
\hline & $\begin{array}{c}\text { \%Dry Ore } \\
\text { Basis }\end{array}$ & $\begin{array}{c}\text { \%Dry Total } \\
\text { Basis }\end{array}$ & $\begin{array}{c}\text { \%Dry Ore } \\
\text { Basis }\end{array}$ & $\begin{array}{c}\text { \%Dry Total } \\
\text { Basis }\end{array}$ & $\begin{array}{l}\text { \%Dry Ore } \\
\text { Basis }\end{array}$ & $\begin{array}{c}\% \text { Dry Total } \\
\text { Basis }\end{array}$ \\
\hline AUS1 fines & 16.7 & & 15.0 & & 11.7 & \\
\hline AUS2 fines & 16.7 & & 15.0 & & 11.7 & \\
\hline AUS3 fines & 33.3 & & 30.0 & & 23.3 & \\
\hline BRA1 fines & 16.7 & & 15.0 & & 11.7 & \\
\hline BRA2 fines & 16.7 & & 15.0 & & 11.7 & \\
\hline Concentrate & 0 & & 10.0 & & 30 & \\
\hline Sub-total Iron ores & 100 & 62.7 & 100.0 & 62.5 & 100 & 62.2 \\
\hline Limestone & & 4.7 to 9.0 & & 5.3 to 9.7 & & 6.9 to 11.2 \\
\hline Serpentine & & 0.1 to 0.4 & & 0.7 to 1.0 & & 1.9 to 2.2 \\
\hline Dolomite & & 5.1 & & 4.2 & & 1.8 \\
\hline Coke & & 4.4 & & 4.4 & & 4.4 \\
\hline Return Fines & & 19.0 & & 19.0 & & 19.0 \\
\hline Hydrated lime & & $0,2,4$ & & $0,2,4$ & & $0,2,4$ \\
\hline
\end{tabular}


min, subsequently desired amount of water was sprayed onto the sinter mixtures in the drum, the granulation continued for a further $8 \mathrm{~min}$ to achieve homogeneity. The rotation speed of drum was kept as $16 \mathrm{rev} / \mathrm{min}$, corresponding to a Froude number of 0.0036 and a space factor of $11 \%$. When it came to the end of granulation, several granulated samples were collected for moisture, granule apparent density and size distribution measurements and XCT characterization. Two repeated granulated samples were dried in an oven at $105^{\circ} \mathrm{C}$ for $8 \mathrm{~h}$ to measure the moisture content, which was expressed as a wet mass basis. Granule apparent density was determined by kerosene displacement, which can be further used for calculating bulk bed porosity. The size distribution was measured by screening on a rotary shaker with a $2^{1 / 2}$ sieve series from 0.25 to $11.2 \mathrm{~mm}$. XCT characterization will be described in Section 2.3.

\subsection{Taguchi Orthogonal Experimental Design}

The packed bed structure of iron ore granules is coupling influenced by multiple factors of moisture, hydrated lime and concentrate levels. A large number of experiments has to be performed and analyzed in order to determine effects of multiple factors on the packed bed properties if using tradition experimental design method, which is cumbersome, time-consuming and expensive. ${ }^{23)}$ To solve the above problems, a simple and efficient approach, the Taguchi orthogonal experimental design, is applied to investigate the individual effect of each of multiple factors under designated ranges on packed bed properties and identify optimum levels of factors in this study.

An L9 orthogonal array was applied to define the experimental conditions. Three granulation factors including moisture, hydrated lime and concentrate were considered in this study, and three levels were selected according to the previous work, ${ }^{19)}$ as shown in Table 2. And Table 3 illustrates the arrangement of the Taguchi orthogonal experiment.

\subsection{X-ray Computed Tomography and Image Process- ing}

Granulated samples were spooned into a standard slender hollow cylindrical funnel, through which the granules fell into a cylindrical container with internal diameter of $77 \mathrm{~mm}$ and height of $85 \mathrm{~mm}$ to form a randomly packed bed for XCT characterization. In this study, the nanoVoxel 4000 scanner was applied to scan the granule packed bed, the scanning parameters set up are listed in Table 4. The resolution was determined as $48 \mu \mathrm{m}$ considering the tradeoff between fine granule size in the packed bed and computational cost.

The processing and analysis of two-dimensional slice images were performed using commercial software. As

Table 2. The level value of each parameter.

\begin{tabular}{lcccc}
\hline \multirow{2}{*}{ Parameter } & A & B & C \\
\cline { 2 - 5 } & 1 & $\begin{array}{c}\text { Moisture } \\
(\text { mass } \%)\end{array}$ & $\begin{array}{c}\text { Hydrated lime } \\
(\text { mass\% } \%\end{array}$ & $\begin{array}{c}\text { Concentrate } \\
(\text { mass\%) }\end{array}$ \\
\hline \multirow{2}{*}{ Level } & 2 & 6.8 & 0 & 0 \\
& 3 & 7.8 & 2 & 10 \\
\hline
\end{tabular}

shown in Fig. 1, the image processing steps are introduced as follows: (1) Extracting the region of interest (ROI). In this study, all the raw grayscale images were cropped into a smaller cylindrical packed bed with a diameter of $55 \mathrm{~mm}$ and height of $53 \mathrm{~mm}$ for further image processing. (2) Noise reduction. This step is applied to minimize noise and smooth images for subsequent image processing steps. (3) Image segmentation. This step is of great significance for distinguishing the pore and solid phase based on the different gray value of slice images, which attribute to the different X-ray absorption of these two phases. After image segmentation, the grey scale images were converted into binary ones, as shown in Fig. 1(d), where blue voxels represent the granules and black the pores. (4) Separating connected granules. Some of the granules appear to be connecting each other after image segmentation by thresholding, which needs to be further separated so as to obtain the ideal packed bed structure.

After the image processing, the three-dimensional structure of the granule packed bed can be reconstructed as represented in Fig. 1(f), from which the detailed information for individual granule and packed bed properties including equivalent diameter and porosity can be calculated. The granule equivalent diameter $\mathrm{D}_{\mathrm{e}}(\mathrm{m})$ and bulk bed porosity $\varepsilon$ were calculated as follows:

$$
\begin{aligned}
D_{e} & =\left(\frac{6}{\pi} V\right)^{1 / 3} \\
\varepsilon & =1-\frac{V_{s}}{V_{d}} \ldots
\end{aligned}
$$

where $\mathrm{V}$ is the volume of individual granule $\left(\mathrm{m}^{3}\right), \mathrm{V}_{\mathrm{s}}$ and

Table 3. Arrangement of Taguchi orthogonal experiment.

\begin{tabular}{clll}
\hline \multirow{2}{*}{ Experiment No. } & \multicolumn{3}{l}{ Parameters and their levels } \\
\cline { 2 - 4 } & A & B & C \\
\hline 1 & 2 & 2 & 2 \\
2 & 2 & 1 & 1 \\
3 & 2 & 3 & 3 \\
4 & 1 & 2 & 1 \\
5 & 1 & 1 & 3 \\
6 & 1 & 3 & 2 \\
7 & 3 & 2 & 3 \\
8 & 3 & 1 & 2 \\
9 & 3 & 3 & 1 \\
\hline
\end{tabular}

Table 4. Set up of the Nanovoxel 4000 scanning conditions.

\begin{tabular}{cc}
\hline Item & Value \\
\hline Voltage $(\mathrm{kV})$ & 200 \\
Current $(\mu \mathrm{A})$ & 200 \\
Exposure time $(\mathrm{s})$ & 0.62 \\
Source-to-sample distance $(\mathrm{mm})$ & 242 \\
Source-to-detector distance $(\mathrm{mm})$ & 640.7 \\
Pixel size $(\mu \mathrm{m})$ & 48 \\
\hline
\end{tabular}




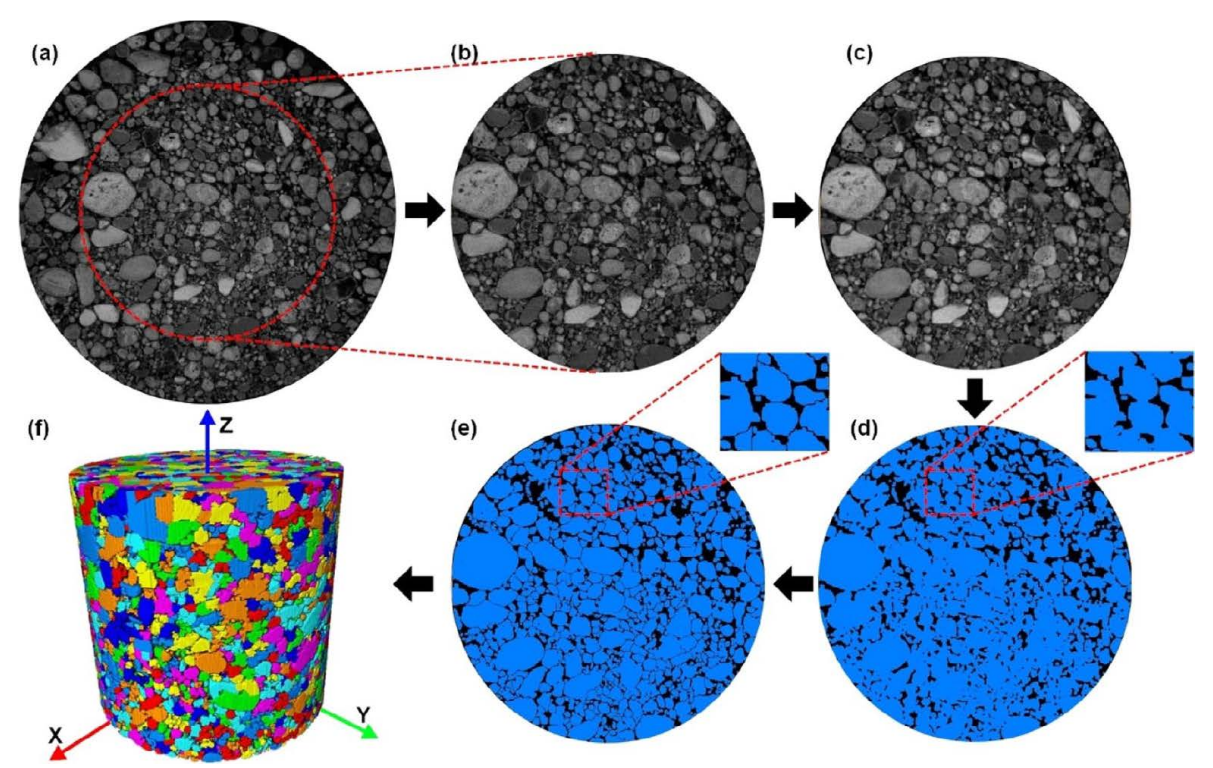

Fig. 1. XCT images processing procedure: (a) original XCT image; (b) selected region of interest (ROI); (c) gray image after noise reduction; (d) binary image after threshold segmentation (blue: granule, black: void); (e) binary image after separating connected granules; (f) reconstructed 3D granule packed bed. (Online version in color.)

Table 5. The XCT results of Taguchi L9 orthogonal array experiments.

\begin{tabular}{|c|c|c|c|c|c|c|c|c|c|}
\hline \multirow{3}{*}{ Exp. No. } & \multicolumn{3}{|c|}{ Conditions } & \multicolumn{6}{|c|}{ Results } \\
\hline & \multirow{2}{*}{$\begin{array}{c}\text { Moisture } \\
\text { (mass\%) }\end{array}$} & \multirow{2}{*}{$\begin{array}{l}\text { Hydrated lime } \\
\text { (mass } \%)\end{array}$} & \multirow{2}{*}{$\begin{array}{l}\text { Concentrate } \\
(\text { mass } \%)\end{array}$} & \multirow{2}{*}{$\begin{array}{c}\text { Equivalent } \\
\text { diameter }(\mathrm{mm})\end{array}$} & \multirow{2}{*}{$\begin{array}{l}\text { Bulk bed } \\
\text { porosity }\end{array}$} & \multicolumn{2}{|r|}{$\gamma_{\text {axial }}$} & \multicolumn{2}{|r|}{$\gamma_{\text {radial }}$} \\
\hline & & & & & & Value & $\mathrm{S} / \mathrm{N}$ ratio $(\mathrm{dB})$ & Value & $\mathrm{S} / \mathrm{N}$ ratio $(\mathrm{dB})$ \\
\hline 1 & 6.8 & 2 & 10 & 3.537 & 0.358 & 0.109 & 19.283 & 1.951 & -5.806 \\
\hline 2 & 6.8 & 0 & 0 & 2.688 & 0.347 & 0.077 & 22.337 & 1.091 & -0.755 \\
\hline 3 & 6.8 & 4 & 30 & 3.292 & 0.396 & 0.031 & 30.229 & 0.825 & 1.673 \\
\hline 4 & 5.8 & 2 & 0 & 1.541 & 0.392 & 0.093 & 20.640 & 0.773 & 2.240 \\
\hline 5 & 5.8 & 0 & 30 & 1.666 & 0.370 & 0.332 & 9.585 & 0.925 & 0.682 \\
\hline 6 & 5.8 & 4 & 10 & 1.992 & 0.390 & 0.113 & 18.908 & 0.921 & 0.719 \\
\hline 7 & 7.8 & 2 & 30 & 4.285 & 0.354 & 0.073 & 22.793 & 0.950 & 0.447 \\
\hline 8 & 7.8 & 0 & 10 & 4.852 & 0.309 & 0.146 & 16.689 & 1.342 & -2.555 \\
\hline 9 & 7.8 & 4 & 0 & 4.752 & 0.384 & 0.087 & 21.180 & 0.842 & 1.496 \\
\hline
\end{tabular}

$\mathrm{V}_{\mathrm{d}}$ are the volumes of the solid phase and the cylindrical computational domain with a diameter of $55 \mathrm{~mm}$ and height of $53 \mathrm{~mm}$, respectively $\left(\mathrm{m}^{3}\right)$.

\section{Results and Discussions}

\subsection{Granule Properties}

Table 5 shows the XCT data results of nine orthogonal array experiments. Take the packed bed of experiment No. 3 (6.8\% moisture, $4 \%$ hydrated lime, $30 \%$ concentrate) as the representative sample, the comparison of granule size distribution by sieving and XCT analysis is shown in Fig. 2. It can be observed that the granule size distribution obtained by XCT analysis is narrower and skewed to the larger granules compared to experimental sieving. The limited spatial resolution of scanner is the major reason to explain this phenomenon. ${ }^{24)}$ The scanning resolution of $48 \mu$ m indicates that the fine granules smaller than it will be ignored during the three-dimensional reconstruction of the packed bed, which leads the size distribution to bias towards the larger granules as shown in Fig. 2. Despite the deviation exists between $\mathrm{XCT}$ analysis and experimental measurement, improving

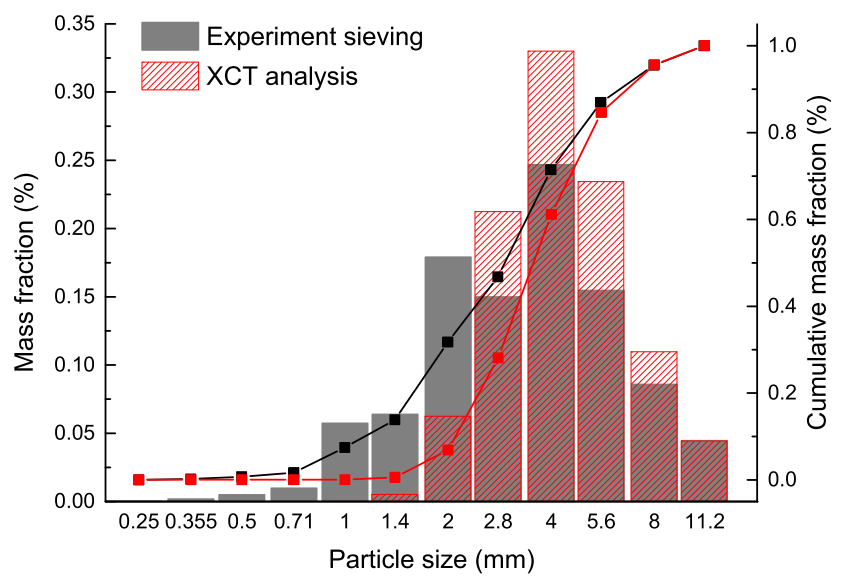

Fig. 2. Comparison of granule size distribution by experimental sieving and XCT analysis. (Online version in color.)

the scanning resolution can effectively reduce the deviation and obtain satisfactory accuracy, leading XCT technique a promising and reliable alternative to get detailed threedimensional structure information of packed bed.

Figure 3 gives the granule size distribution of nine 
packed beds from orthogonal experiments. It can be clearly seen that moisture is the dominant factor affecting the granule size distribution. As the moisture increases, the granule mean diameter significantly increases from about $1.5 \mathrm{~mm}$ at $5.8 \%$ moisture to $4.8 \mathrm{~mm}$ at $7.8 \%$ as depicted in Fig. 4 . This conclusion is consistent with open literature that water addition leads to the larger granule size and narrower size distribution. ${ }^{7-9,14,18,19,25)}$ The granule morphologies under different moisture conditions are presented in Fig. 5, it can be found visually that when moisture is as low as $5.8 \%$, there are few fine powders adhered to the granule surfaces, and granule size is small. The granules gradually growth with the moisture increases to $6.8 \%$, and their surfaces are getting rough with fine powders adhered to. This phenomenon of granule growth becomes more pronounced at $7.8 \%$ moisture. Compared to the significant effect of moisture on granule growth, the effects of hydrated lime and concentrate levels on granule size and size distribution are unclear, which need further analysis.

\subsection{Porosity Distribution of Granule Packed Bed}

Porosity distribution of iron ore granule packed bed is a key to govern the bed permeability and further influence yield and sinter strength through affecting the energy effi-

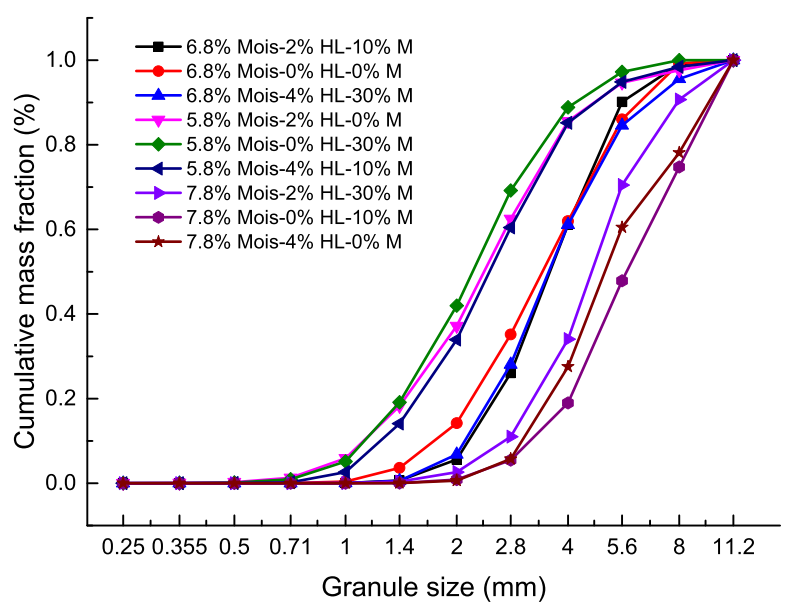

Fig. 3. Granule size distribution of all nine packed beds from orthogonal experiments by XCT analysis. (Online version in color.)

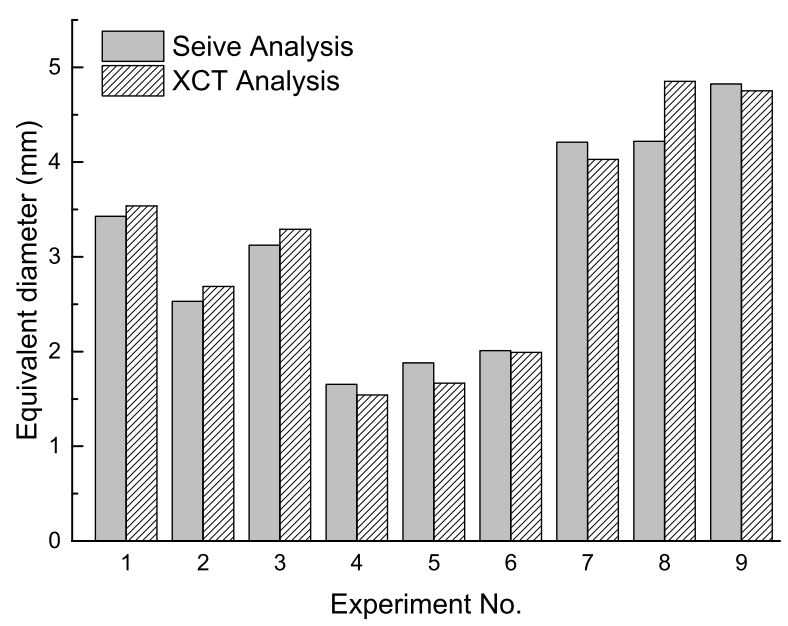

Fig. 4. Equivalent diameter of granules obtained by experimental sieving and XCT analysis. ciency during the sintering process. Properly and uniformly arranged packed bed porosity distribution is desirable for sintering for providing more even sintering temperatures, which leads to uniform and high-quality sinter products.

Axial porosity distribution of granule packed bed was determined by the porosity of each XCT slice along bed height direction (z-direction), which is illustrated in Fig. 6. As is shown, axial porosity presents random and irregular fluctuates along the height of the packed bed for each experiment case. However, the overall trend is that the axial porosity decreases from top to bottom of the packed bed.

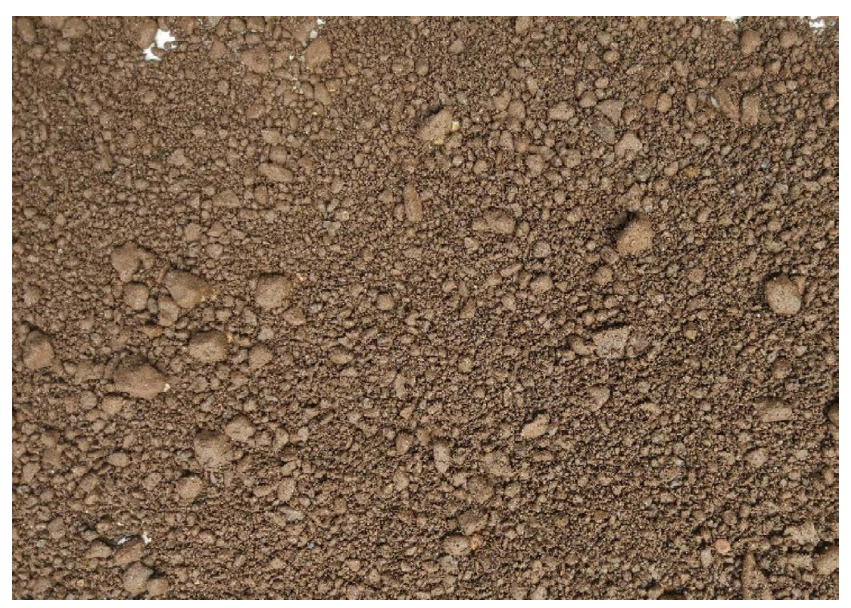

(a) $5.8 \%$ moisture, $2 \%$ hydrated lime, $0 \%$ concentrate

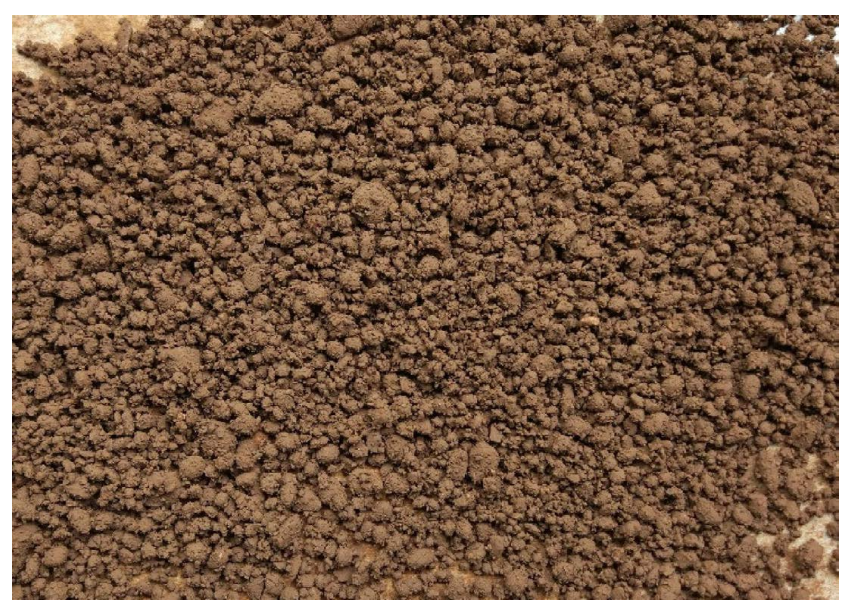

(b) $6.8 \%$ moisture, $2 \%$ hydrated lime, $10 \%$ concentrate

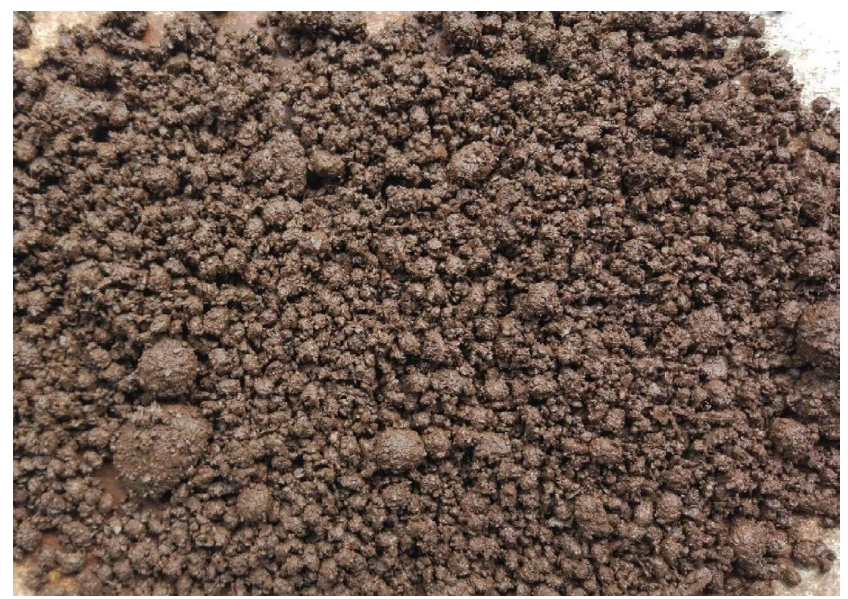

(c) $7.8 \%$ moisture, $0 \%$ hydrated lime, $10 \%$ concentrate

Fig. 5. Granule morphologies after granulation under different moisture. (Online version in color.) 


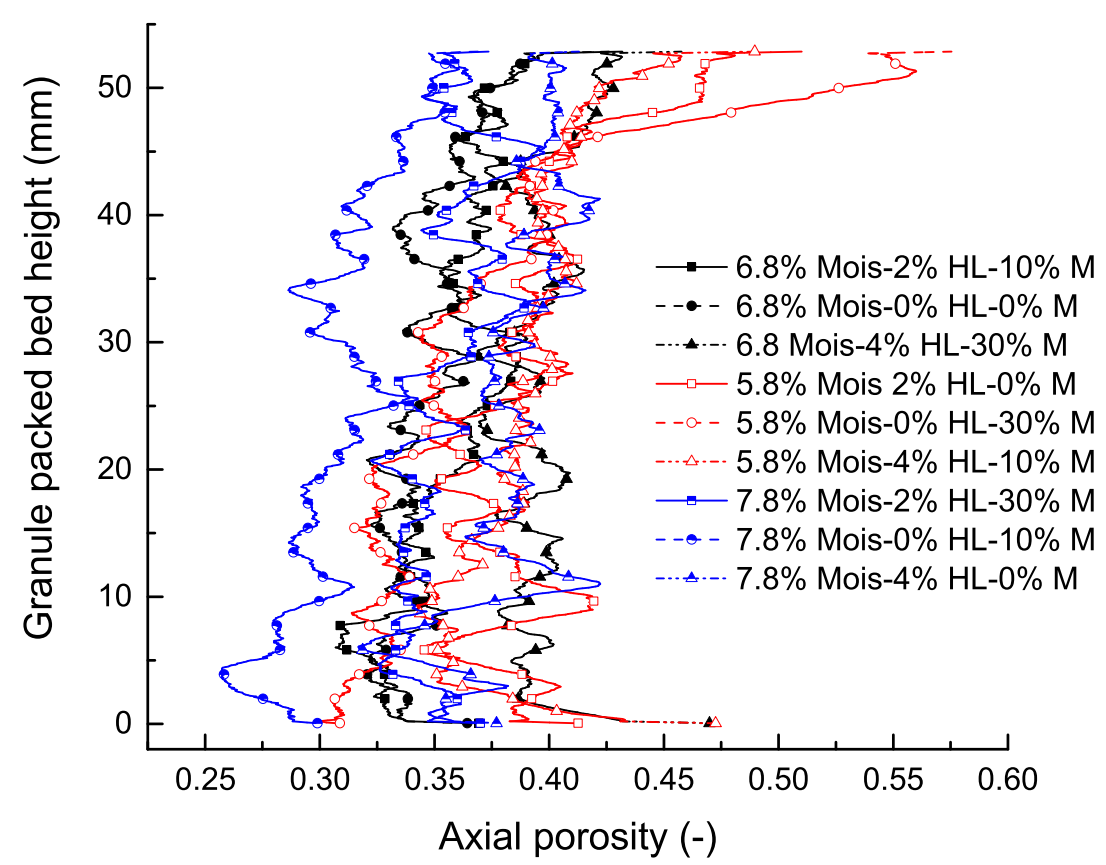

Fig. 6. Axial porosity distribution alone granule packed bed height. (Online version in color.)

During the packing process, the iron ore granules at the lower part appeared certain of tamping caused by adhering layer deformation under the weight of granules above, ${ }^{26)}$ then fine granules in the upper part of the packed bed would fall down to occupy the voids in the lower part, which led to the denser packing at the lower part of the packed bed. ${ }^{27,28)}$ The porosity at the top and bottom of the packed bed exhibits a significant increase, which can be explained by wall effect, namely influenced by top and bottom wall of the container. Both topmost and bottommost granules of the packed bed were forced to form neatly arranged layers along the walls of top and bottom, and due to the point contact of granules with container wall, the porosity at the wall is higher than the other part of packed bed. ${ }^{29)}$ The granule size, size distribution and shapes are considered to contribute to varied axial porosity between different experiment cases as shown in Fig. 6, which are strongly related to the moisture and feeding mixtures characteristics, as well as their relative content. This will be discussed in detail in the following section.

Radial porosity distribution of granule packed bed is shown in Fig. 7. The radial distance is defined as the dimensionless radius $r / R$, where $r$ is the distance from the center of the cylindrical packed bed, and $\mathrm{R}$ is bed radius. It is worth to be mentioned that, in order to obtain the porosity distribution of bulk packed bed from the perspective of engineering practice, the radial porosity here was determined by the porosity of XCT slices perpendicular to the packed bed height (z-direction) and along two orthogonal radial directions ( $\mathrm{x}$ - and $\mathrm{y}$-direction), which differs from the definition through the porosity of a series of concentric annuli with equal thickness in most open literature. It is observed that the radial porosity distribution of packed bed is consistent in two orthogonal radial directions. Overall, the radial porosity appears a symmetric parabolic distribution, where the radial porosity obtains a minimum of 0.3 at the circle center and increases sharply near the container wall along the radial direction of the packed bed. It is noticed that the growth rate of radial porosity significantly increases at the region of $r>$ $0.75 \mathrm{R}$ compared to the inside area of the packed bed, which is contributed by the wall effect.

To figure out the uniformity of packed bed porosity distribution affected by moisture, hydrated lime and concentrate levels, the axial and radial porosity segregation degrees are defined quantitatively as follows:

$$
\begin{gathered}
\gamma_{\text {axial }}=\frac{\varepsilon_{\mathrm{a}, \mathrm{top}}-\varepsilon_{a, \mathrm{btm}}}{\varepsilon_{a, \mathrm{mid}}} . \\
\gamma_{\text {radial }}=\frac{\varepsilon_{r, \text { out }}-\varepsilon_{r, \text { in }}}{\varepsilon_{r, \text { mid }}} .
\end{gathered}
$$

where $\gamma_{\text {axial }}$ and $\gamma_{\text {radial }}$ are the axial and radial porosity segregation degrees of granule packed bed, respectively. For axial direction, the granule packed bed is divided into three parts evenly along the bed height, namely top, middle and bottom parts, the mean porosity of each region is expressed as $\varepsilon_{\mathrm{a}, \text { top }}, \varepsilon_{\mathrm{a} \text {, mid }}$ and $\varepsilon_{\mathrm{a}, \mathrm{btm}}$. For radial direction, the packed bed is divided into the inner, middle and outer parts symmetrically along the diameter direction, and the mean porosity of each region is $\mathcal{E}_{\mathrm{r} \text {, out }} \mathcal{E}_{\mathrm{r} \text {, mid }}$ and $\mathcal{E}_{\mathrm{r} \text {, in }}$, respectively, as illustrated in Fig. 8. The axial and radial segregation degrees calculated by the Eqs. (3) and (4) are listed in Table 5.

\subsection{Analysis of the $\mathbf{S} / \mathbf{N}$ Ratio for Porosity Segregation}

In Taguchi orthogonal experimental design, a signal-tonoise $(\mathrm{S} / \mathrm{N})$ ratio $\eta$ is used to evaluate the deviation of output characteristics from the desirable value and the greater $\mathrm{S} / \mathrm{N}$ ratio corresponds the better quality characteristics. The $\mathrm{S} / \mathrm{N}$ ratio $\eta$ is defined as:

$$
\eta=-10 \log (\text { M.S.D. })
$$

where M.S.D is the mean-square deviation for the output characteristics.

In general, there are three categories of output characteristics according to the desirable value types: the-lowerthe-better, the higher-the-better, and the-nominal-the-better. 


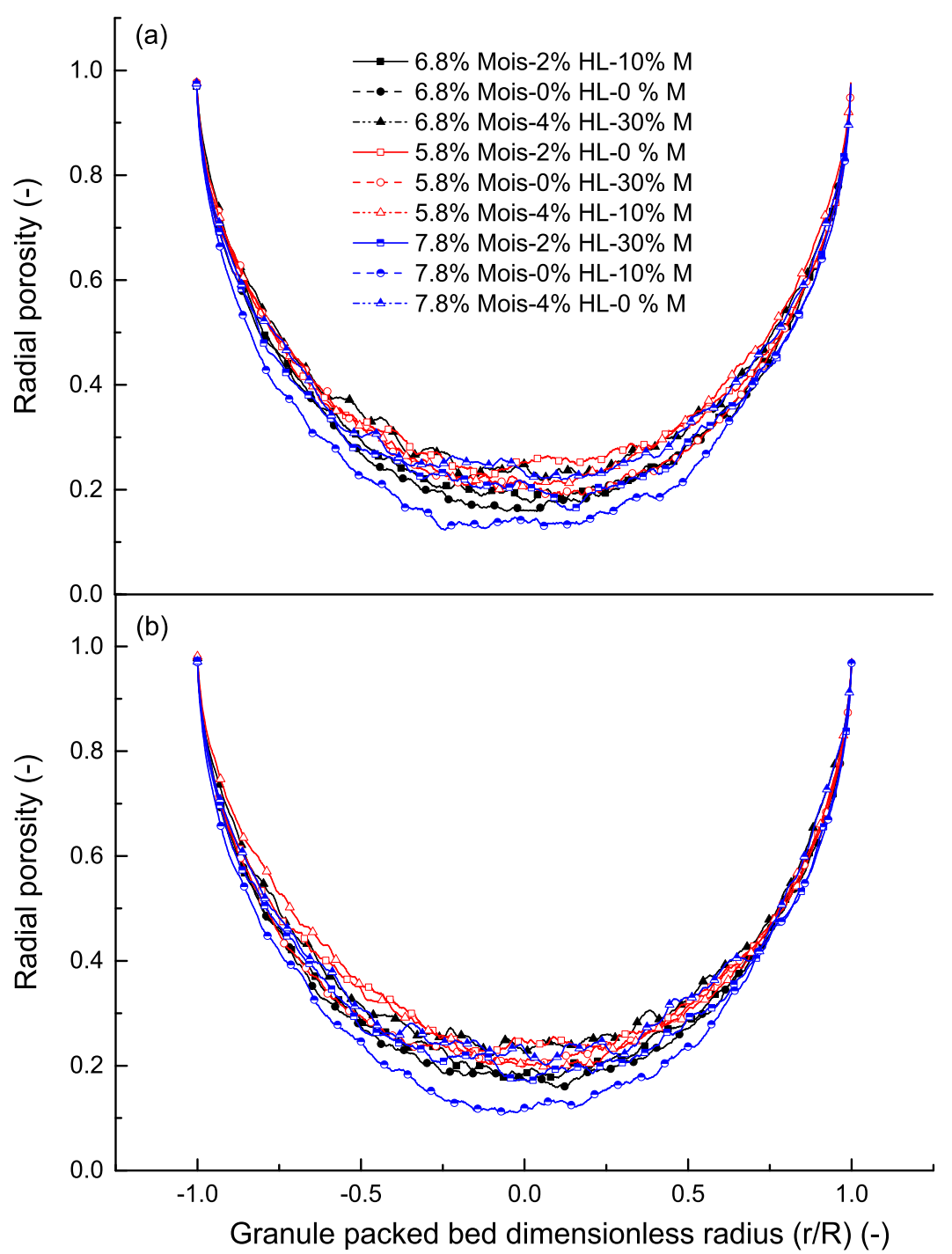

Fig. 7. Radial porosity distribution alone (a) $\mathrm{Y}$ and (b) $\mathrm{X}$ direction of granule bed. (Online version in color.)

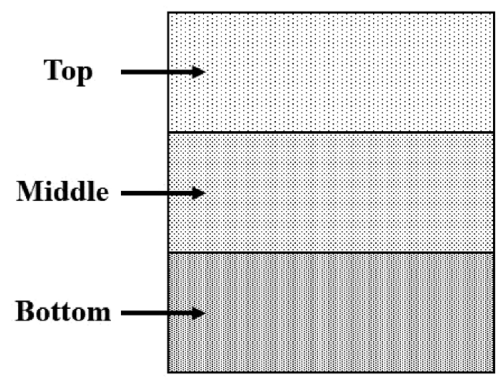

(a)

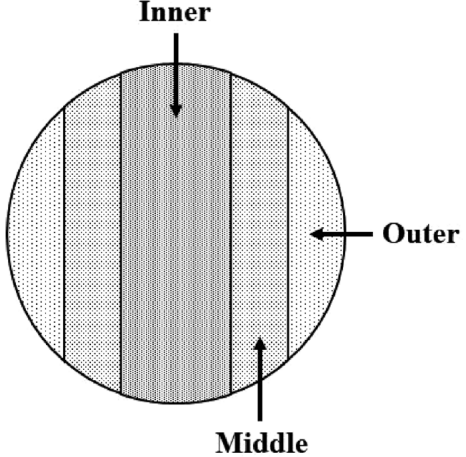

(b)

Fig. 8. Schematic diagram of region division in granule packed bed according to porosity segregation degree definition: (a) axial segregation; (b) radial segregation.

In order to guarantee the uniformity of the granule packed bed, the porosity segregation degrees must be as low as possible, namely, the-lower-the-better output characteristic should be taken. The M.S.D for the-lower-the-better output characteristic is expressed as:

$$
\text { M.S.D. }=\frac{1}{m} \sum_{i=1}^{m} S_{i}^{2}
$$

where $m$ is the number of the repeated tests and $\mathrm{S}_{i}$ is the value of porosity segregation degree obtained from the $i$ th test.

The $\mathrm{S} / \mathrm{N}$ ratios of axial and radial porosity segregation degrees under the designated moisture, hydrated lime and concentrate levels are listed in Table 5, and corresponding $\mathrm{S} / \mathrm{N}$ ratio responses are shown in Table 6. The difference between the maximum and minimum values of $\mathrm{S} / \mathrm{N}$ ratio 
Table 6. $\mathrm{S} / \mathrm{N}$ ratio response for axial and radial porosity segregation degrees.

\begin{tabular}{ccccc}
\hline \multirow{2}{*}{ Parameter } & A & B & C \\
\cline { 2 - 5 } & Level 1 & 16.378 & 16.204 & 21.386 \\
& Level 2 & 23.950 & 20.905 & 18.293 \\
$\gamma_{\text {axial }}$ & Level 3 & 20.221 & 23.439 & 20.869 \\
& Max-Min & 7.572 & 7.235 & 3.093 \\
& Rank & 1 & 2 & 3 \\
\hline \multirow{4}{*}{$\gamma_{\text {radial }}$} & Level 1 & 1.214 & -0.876 & 0.994 \\
& Level 2 & -1.629 & -1.040 & -2.547 \\
& Level 3 & -0.204 & 1.296 & 0.934 \\
Max-Min & 2.843 & 2.336 & 3.541 \\
& Rank & 2 & 3 & 1 \\
\hline
\end{tabular}

The total mean $\mathrm{S} / \mathrm{N}$ ratio for $\gamma_{\text {axial }}=20.183 \mathrm{~dB}$;

The total mean $\mathrm{S} / \mathrm{N}$ ratio for $\gamma_{\text {radial }}=-0.207 \mathrm{~dB}$.

(i.e., Max-Min) reflects the relative importance of three selected parameters of moisture, hydrated lime and concentrate levels on porosity segregation. The higher of this value corresponds to the greater contribution of the factor to the porosity segregation. For axial porosity segregation, the moisture is the most influential factor, followed by hydrated lime and concentrate contributes least to axial porosity segregation. For radial porosity segregation, the relative importance of three selected parameters is shown as concentrate $>$ moisture $>$ hydrate lime. Figure $\mathbf{9}$ gives the mean $\mathrm{S} / \mathrm{N}$ ratio of axial and radial porosity segregation for each factor at three designated levels. For axial porosity segregation, the mean $\mathrm{S} / \mathrm{N}$ ratios are observed to increase first then decrease with moisture, monotonic increase with hydrated lime levels and decrease first then increase with concentrate levels. For radial porosity segregation, moisture, hydrated lime and concentrate levels share the same trend of decreasing first then increasing with designed levels. It is clear from the Fig. 9 that the optimum combination for decreasing axial and radial porosity segregation is determined as $6.8 \%$ moisture, $4 \%$ hydrated lime, $0 \%$ concentrate and $5.8 \%$ moisture, $4 \%$ hydrated lime, $0 \%$ concentrate, respectively, which provides the theoretical guidance of engineering practice for achieving homogeneous packed bed of iron ore granules.

\subsection{ANOVA Analysis}

The analysis of variance (ANOVA) is a statistical method to determine the contribution of individual factor to the overall variation in a dataset. In this study, ANOVA analysis based $\mathrm{F}$ test is conducted to compare the statistical significance of three selected factors of moisture, hydrated lime and concentrate levels on granule size, bulk bed porosity as well as axial and radial porosity segregation degree, the ANOVA analysis results are listed in Table 7. The significance of three selected factors in ANOVA is determined by $\mathrm{F}$ value. In general, when $\mathrm{F}$ is greater than 9.00, the value of $\mathrm{F}_{0.10(2,2)}$ read in Fisher tables, it indicates that the designed factor has a significant effect on the quality characteristics.

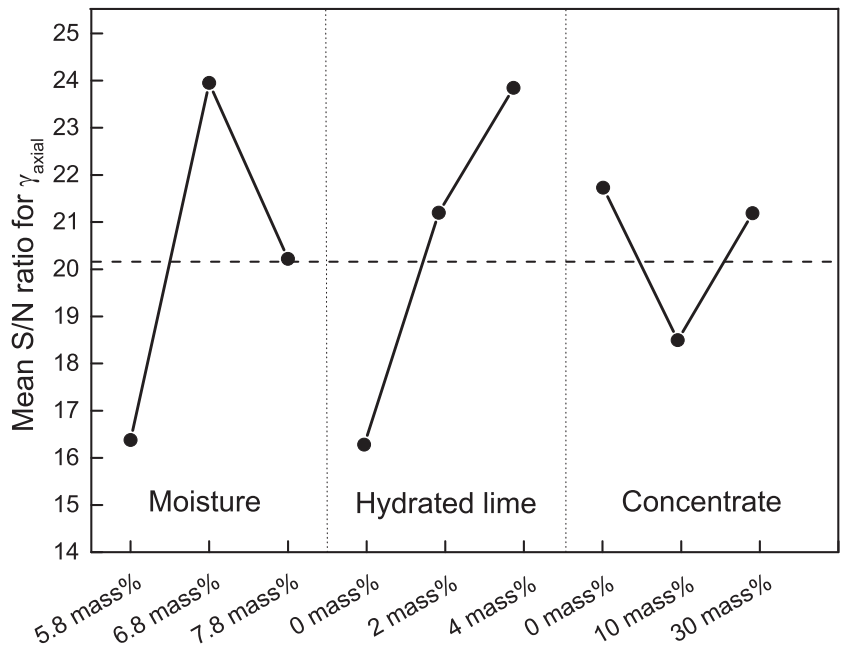

(a) Mean $\mathrm{S} / \mathrm{N}$ ratio for $\gamma_{\text {axial }}$

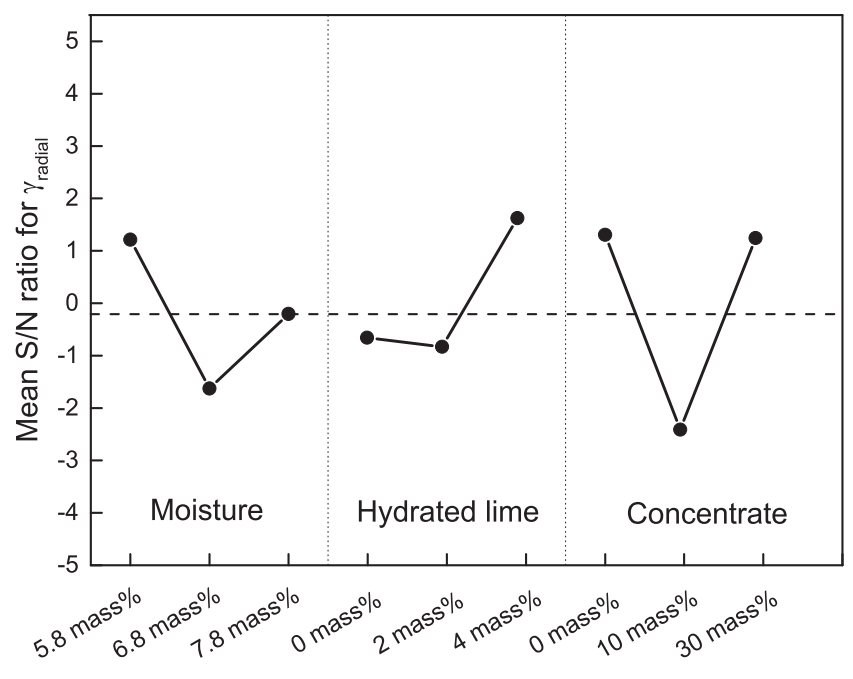

(b) Mean $\mathrm{S} / \mathrm{N}$ ratio for $\gamma_{\text {radial }}$

Fig. 9. Mean $\mathrm{S} / \mathrm{N}$ ratio of three selected parameters at the designated levels for axial and radial porosity segregation degree.

It can be found that moisture is the dominant factor affecting the granule equivalent diameter with a largest $\mathrm{F}$ value of 72.17 and major percent contribution of $94.92 \%$ compared to the hydrated lime and concentrate levels, which is consistent with the discussion in Section 3.1. During the granulation process, the added water served as a binding liquid to form water bridges between granules. With the water addition increasing, the states of liquid bridge formation change from the pendular to funicular and then to the capillary state ${ }^{30)}$ accompanying layering of fines adhering onto nuclei granules, granule nucleation and coalescence due to capillary force induced from the liquid bridges, ${ }^{5,18,31,32)}$ which leads to the granule growth to produce larger granules. The presence of water is essential for generating the capillary force and governing granule growth mechanisms, which is well explained that moisture has the greatest influence on granule size. Compared to moisture, the effects of hydrated lime and concentrate are much weaker with the percent contribution of $0.98 \%$ and $2.78 \%$, respectively. Hydrated lime and concentrate are performed as ultra-fines for their mean volume diameter are $12.7 \mu \mathrm{m}$ and $92.3 \mu \mathrm{m}$, respectively. According to open literature, the addition of fines 
ISIJ International, Vol. 60 (2020), No. 6

Table 7. Results of ANOVA analysis.

\begin{tabular}{|c|c|c|c|c|c|c|}
\hline Quality characteristic & Parameter & $\begin{array}{l}\text { Degrees of } \\
\text { freedom }\end{array}$ & $\begin{array}{l}\text { Sum of } \\
\text { squares }\end{array}$ & $\begin{array}{c}\text { Mean } \\
\text { squares }\end{array}$ & $\mathrm{F}$ & $\begin{array}{c}\text { Contribution } \\
(\%)\end{array}$ \\
\hline \multirow{5}{*}{$\begin{array}{c}\text { Granule equivalent } \\
\text { diameter }\end{array}$} & Moisture & 2 & 12.59 & 6.29 & 72.17 & 94.92 \\
\hline & Hydrated lime & 2 & 0.13 & 0.06 & 0.74 & 0.98 \\
\hline & Concentrate & 2 & 0.37 & 0.18 & 2.12 & 2.78 \\
\hline & Error & 2 & 0.17 & 0.09 & - & 1.32 \\
\hline & Total & 8 & 12.26 & 6.62 & - & 100 \\
\hline \multirow{5}{*}{$\begin{array}{l}\text { Bulk } \\
\text { porosity }\end{array}$} & Moisture & 2 & 0.0018 & 0.0009 & 20.51 & 29.12 \\
\hline & Hydrated lime & 2 & 0.0035 & 0.0017 & 38.80 & 55.10 \\
\hline & Concentrate & 2 & 0.0091 & 0.0005 & 10.11 & 14.36 \\
\hline & Error & 2 & 0.0001 & 0.0000 & - & 1.42 \\
\hline & Total & 8 & 0.0063 & 0.0032 & - & 100 \\
\hline \multirow{5}{*}{$\begin{array}{l}\text { Axial porosity } \\
\text { segregation }\end{array}$} & Moisture & 2 & 86.01 & 43.01 & 1.50 & 35.76 \\
\hline & Hydrated lime & 2 & 80.88 & 40.44 & 1.41 & 33.62 \\
\hline & Concentrate & 2 & 16.46 & 8.23 & 0.29 & 6.84 \\
\hline & Error & 2 & 57.19 & 28.60 & - & 23.78 \\
\hline & Total & 8 & 240.54 & 120.27 & - & 100 \\
\hline \multirow{5}{*}{$\begin{array}{l}\text { Radial porosity } \\
\text { segregation }\end{array}$} & Moisture & 2 & 12.12 & 6.06 & 2.59 & 23.47 \\
\hline & Hydrated lime & 2 & 10.20 & 5.10 & 2.18 & 19.74 \\
\hline & Concentrate & 2 & 24.66 & 12.33 & 5.28 & 47.74 \\
\hline & Error & 2 & 4.68 & 2.34 & - & 9.05 \\
\hline & Total & 8 & 51.66 & 25.83 & - & 100 \\
\hline
\end{tabular}

results in more complex granule growth mechanisms. ${ }^{10)}$ With adhering fines addition, a fraction of fine granules participate in the secondary agglomeration mechanisms such as coalescence, and fewer fines are available to act as an adhering layer on the nuclei granules, which inhibits the growth of coarse granules and decreases the mean size of the granules. ${ }^{10,16,17)}$ However, this effect is minor compared to that of moisture.

As for bulk porosity of granule packed bed, the moisture, hydrated lime and concentrate levels are all found to have a significant influence with the percent contribution order of hydrated lime $(55.10 \%)>$ moisture $(29.12 \%)>$ concentrate $(14.36 \%)$. As ultra-fines, hydrated lime and concentrate are usually adhered onto coarse granules to form adhering layers during granulation, however, the difference in physical properties between them results in their different roles in the granulation process. As mentioned above, the apparent density and granule size of hydrated lime are much smaller than concentrate, leading a larger granule volume as well as larger granule number per unit weight, which provides more contact points between granules and hence the effect of capillary force on porosity is more pronounced for hydrated lime under given moisture. ${ }^{32)}$ In addition, compared to the smooth surface of concentrate, the surface of hydrated lime is much rougher, which provides more tightly bonding by water bridges, therefore increases the cohesion strength of granules adhering layer and hinders tamping of granule during packing process, which further contributes to the packed bed porosity. ${ }^{26,32)}$ The comprehensive effect of the above explains the most notable influence of hydrated lime on bulk bed porosity. Bulk bed porosity affected by moisture is a well-established topic and it is widely accepted that three distinct regions can be divided in the porosity-moisture curve: at low moistures, the porosity of packed bed increases with increasing moisture due to the tightening of the granule size distribution by the onset of granulation. The balance of two reversed effects of granule deformation and the tightening of the granule size distribution bring to a maximum bulk porosity at intermediate moistures. At higher moistures, the thicker adhering layer is built up around the nuclei granules, leading the granule deformation being the dominant factor on packed bed porosity. ${ }^{8,9,18)}$ The influence of concentrate on bed porosity can be explained by the thicker and weaker adhering layering with concentrate addition, which tends to deform during the packing process. Besides, incorporating concentrate also leads to the formation of more spherical granules, which provides less granule-to-granule interlock and hence impedes forming a more compact packed bed with high porosity. ${ }^{10,17,19)}$

Limited by the much smaller size of granule packed bed used for scanning, the porosity segregation of packed bed is not significant compared to the packed bed in actual industrial sintering. Thus the three selected factors are found to influence the axial and radial porosity segregation insignificantly as shown in Table 7 . Nevertheless, the relative importance of the three selected factors on porosity segregation makes sense for industrial iron ore sintering. The insignificant contribution of three selected factors is shown as moisture $(35.76 \%)>$ hydrated lime $(33.62 \%)>$ concentrate $(6.84 \%)$ for axial porosity segregation and concentrate $(47.74 \%)>$ moisture $(23.47 \%)>$ hydrated lime $(19.74 \%)$ for radial porosity segregation. This finding agrees with 
the results observed from the $\mathrm{S} / \mathrm{N}$ ratio analysis in Section 3.3. Studies have shown that the porosity fluctuation along packed bed height increases as the tube to granule diameter ratio decreases, ${ }^{27)}$ thus for a given container diameter, the larger granule size is, the greater axial porosity fluctuates. It can be concluded from the foregoing discussion that moisture is the dominant factor affecting granule size, and therefore contributes most to axial porosity segregation. Contrary to axial porosity segregation, concentrate level is found to has the greatest contribution on radial porosity segregation in spite of the effects of the three selected factors are all not significant, which is guessed to be responsible by slight granule accumulation close to cylindrical container center rather than its wall during the drop of granules with thick and weak adhering layer when adding concentrate.

\section{Conclusion}

In this study, Taguchi orthogonal array experiments were conducted to investigate the effects of moisture, hydrated lime and concentrate levels on granule properties and porosity distribution of sintering packed bed obtained by the non-destructive XCT technique. The following conclusions can be drawn:

(1) XCT was proved to be an effective non-destructive technique to characterize the internal three-dimensional structure properties qualitatively such as granule size, bulk porosity and porosity distribution of iron ore sintering packed bed. And more satisfactory results of higher accuracy can be obtained by improving the resolution of XCT.

(2) Moisture is the dominant factor of affecting granule size with a major percent contribution of $94.92 \%$ compared to the hydrated lime and concentrate levels. Moisture, hydrated lime and concentrate levels are all significantly affect the bulk bed porosity, and the percent contribution order of these three selected factors is shown as hydrated lime $(55.10 \%)>$ moisture $(29.12 \%)>$ concentrate $(14.36 \%)$.

(3) The whole packed bed exhibits significant inhomogeneity. It is observed that axial porosity increases from the bottom upwards along the packed bed height, and radial porosity appears a symmetric parabolic distribution where the porosity achieves the minimum of 0.3 at bed center and increases sharply near the wall due to the wall effect. Though none of the three selected factors is found to significantly influence the porosity segregation of packed bed, the obtained relative importance of the factors is valuable. The insignificant contribution order is shown as moisture $(35.76 \%)>$ hydrated lime $(33.62 \%)>$ concentrate $(6.84 \%)$ for axial porosity segregation and concentrate $(47.74 \%)>$ moisture $(23.47 \%)>$ hydrated lime $(19.74 \%)$ for radial porosity segregation.

(4) In order to achieve homogeneous packed bed of iron ore granules and improve sintering process for obtaining high-quality sinter products, the optimum granulation factors combination for decreasing axial and radial porosity segregation are determined as $6.8 \%$ moisture, $4 \%$ hydrated lime, $0 \%$ concentrate and $5.8 \%$ moisture, $4 \%$ hydrated lime, $0 \%$ concentrate, respectively.

\section{Acknowledgment}

This work was supported by the National Science Fund for Distinguished Young Scholars (No. 51825605) and National Natural Science Foundation of China (51906212).

\section{REFERENCES}

1) S. Ergun: Chem. Eng. Prog., 48 (1952), 89.

2) D. Fernández-González, I. Ruiz-Bustinza, J. Mochón, C. GonzálezGasca and L. F. Verdeja: Miner. Process. Extr. Metall. Rev., 38 (2017), 36. https://doi.org/10.1080/08827508.2016.1244059

3) J. P. Zhao, C. E. Loo and R. D. Dukino: Combust. Flame, 162 (2015), 1019. https://doi.org/10.1016/j.combustflame.2014.09.026

4) H. Zhou, M. X. Zhou, Z. H. Liu, M. Cheng, K. Z. Qiu and K. F. Cen: ISIJ Int., 55 (2015), 2556. https://doi.org/10.2355/isijinternational. ISIJINT-2015-311

5) J. D. Litster: Powder Technol., 62 (1990), 125. https://doi. org/10.1016/0032-5910(90)80075-A

6) R. Venkataramana, P. C. Kapur and S. S. Gupta: Chem. Eng. Sci., 57 (2002), 1685. https://doi.org/10.1016/S0009-2509(02)00070-2

7) C. C. Yang, D. Q. Zhu, J. Pan and L. M. Lu: ISIJ Int., 58 (2018), 141. https://doi.org/10.2355/isijinternational.ISIJINT-2018-141

8) R. Venkataramana, S. S. Gupta and P. C. Kapur: Int. J. Miner. Process., 57 (1999), 43. https://doi.org/10.1016/S0301-7516(99)00005-8

9) J. Hinkley, A. G. Waters, D. O'Dea and J. D. Litster: Int. J. Miner. Process., 41 (1994), 53. https://doi.org/10.1016/03017516(94)90005-1

10) A. M. Nyembwe, R. D. Cromarty and A. M. Garbers-Craig: Miner. Process. Extr. Metall. Rev., 38 (2017), 388. https://doi.org/10.1080/0 8827508.2017 .1323750

11) H. X. Mao, R. Zhang, X. W. Lv, C. G. Bai and X. B. Huang: ISIJ Int., 53 (2013), 1491. https://doi.org/10.2355/isijinternational.53.1491

12) T. Maeda, C. Fukumoto, T. Matsumura, K. Nishioka and M. Shimizu: ISIJ Int., 45 (2005), 477. https://doi.org/10.2355/isijinternational.45.477

13) T. Maeda, Y. Hayashi, K. Ohno and K. Kunitomo: Tetsu-to-Hagané, 103 (2017), 246 (in Japanese). https://doi.org/10.2355/tetsutohagane. TETSU-2016-074

14) J. D. Litster and A. G. Waters: Powder Technol., 55 (1988), 141. https://doi.org/10.1016/0032-5910(88)80097-4

15) J. Khosa and J. Manuel: ISIJ Int., 47 (2007), 965. https://doi. org/10.2355/isijinternational.47.965

16) A. M. Nyembwe, R. D. Cromarty and A. M. Garbers-Craig: Powder Technol., 295 (2016), 7. https://doi.org/10.1016/j.powtec.2016.03.010

17) A. M. Nyembwe, R. D. Cromarty and A. M. Garbers-Craig: Miner. Process. Extr. Metall. Rev., 125 (2016), 178. https://doi.org/10.1080 /03719553.2016.1180033

18) H. Zhou, M. X. Zhou, D. P. O'Dea, B. G. Ellis, J. Z. Chen and M. Cheng: ISIJ Int., 56 (2016), 1920. https://doi.org/10.2355/isijinternational.ISIJINT-2016-298

19) M. X. Zhou, H. Zhou, D. P. O’Dea, B. G. Ellis, T. Honeyands and X. T. Guo: ISIJ Int., 57 (2017), 1004. https://doi.org/10.2355/ isijinternational.ISIJINT-2016-734

20) S. Dale, C. Wassgren and J. Litster: Powder Technol., 264 (2014), 550. https://doi.org/10.1016/j.powtec.2014.06.009

21) B. H. Yang, A. X. Wu, X. X. Miao and J. Z. Liu: Trans. Nonferr. Met. Soc. China, 24 (2014), 833. https://doi.org/10.1016/S10036326(14)63131-9

22) A. Khalili, M. Matyka, R. M. Mohammadi, J. Weise and M. M. M. Kuypers: Powder Technol., 338 (2018), 830. https://doi. org/10.1016/j.powtec.2018.07.039

23) M. N. Islam and A. Pramanik: J. Adv. Manuf. Syst., 15 (2016), 151. https://doi.org/10.1142/S0219686716500116

24) K. S. Augusto and S. Paciornik: Mater. Res., 21 (2018), 1516. http:// dx.doi.org/10.1590/1980-5373-mr-2017-0621

25) M. Matsumura and T. Kawaguchi: Tetsu-to-Hagané, 87 (2001), 290 (in Japanese). https://doi.org/10.2355/tetsutohagane1955.87.5 290

26) M. X. Zhou, H. Zhou, T. Honeyands, D. P. O'dea, B. G. Ellis, P. N. Ma and Y. W. Li: Powder Technol., 338 (2018), 599. https://doi. org/10.1016/j.powtec.2018.07.051

27) P. G. Zhang, J. J. Cai, H. Dong, Z. Cao and Y. W. Yang: Ind. Eng. Chem. Res., 51 (2012), 10165. https://doi.org/10.1021/ie300801e

28) C. G. du Toit: Nucl. Eng. Des., 238 (2008), 3073. https://doi. org/10.1016/j.nucengdes.2007.12.018

29) R. F. Benenati and C. B. Brosilow: AIChE J., 8 (1962), 359. http:// doi.org/10.1002/aic.690080319

30) G. I. Tardos, M. I. Khan and P. R. Mort: Powder Technol., 94 (1997), 245. https://doi.org/10.1016/S0032-5910(97)03321-4

31) K. V. S. Sastry, P. Dontula and C. Hosten: Powder Technol., 130 (2003), 231. https://doi.org/10.1016/S0032-5910(02)00271-1

32) H. Louati, D. Oulahna and A. de Ryck: Powder Technol., 315 (2017), 398. https://doi.org/10.1016/j.powtec.2017.04.030 